\title{
Executive Functions and Physical Aggression after Controlling for Attention Deficit Hyperactivity Disorder, General Memory, and IQ
}

\author{
Jean R. Séguin and Bernard Boulerice \\ Université de Montréal, Canada \\ Philip W. Harden \\ Montreal Children's Hospital, Canada \\ Richard E. Tremblay \\ Université de Montréal, Canada \\ Robert O. Pihl \\ McGill University, Montréal, Canada
}

\begin{abstract}
This study examined the role of ADHD in the association between physical aggression and two types of executive functions. Boys received a cognitive-neuropsychological test battery over the ages of 13, 14, and 15 years. Diagnostic Interview Schedule for Children (DISC 2.25) data were collected from the boys and one parent between ages 14 and 16, and an IQ estimate was obtained at age 15. Three groups, differing in stability and level of physical aggression since kindergarten, were formed: Stable Aggressive, Unstable Aggressive, and Nonaggressive. Composite scores of validated executive function tests of working memory representing subjective ordering and conditional association learning were formed. A MANCOVA $(N=149)$ using ADHD status, teacher-rated negative emotionality, general memory abilities, and IQ as covariates was performed on the two composite scores. ADHD and teacher-rated emotionality did not provide significant adjustment to the dependent variables. Number of ADHD symptoms was negatively associated only with general memory and IQ. General memory contributed significantly to adjusting for conditional association test scores. Group differences indicated lower conditional association scores for Unstable Aggressive boys relative to the other groups. Both IQ and general memory abilities interacted with subjective ordering within the groups. Specifically, Stable Aggressive boys performed poorly on this measure and did not benefit from increases in IQ whereas Nonaggressive boys performed best and were not disadvantaged by lower general memory abilities. This suggests a relationship exists between aspects of working memory and a history of physical aggression regardless of ADHD and IQ.
\end{abstract}

Keywords: ADD/ADHD, aggression, executive function, intelligence, cognition, hyperactivity.

Abbreviations: CD: Conduct Disorder; DISC: Diagnostic Interview Schedule for Children; NSCA: Non-Spatial Conditional Association test; SCA: Spatial Conditional Association test; SOP: Self-Ordered Pointing test.

The role of cognitive factors in psychopathology has been the object of a renewed interest. Studies of externalising disorders have led several authors to focus

Requests for reprints to: Jean R. Séguin, PhD, Research Unit on Childhood Psychosocial Maladjustment, Université de Montréal, 3050 Édouard Montpetit, PO Box 6128, Succ. Centre Ville, Montréal, Québec, Canada H3T 1J7 (E-mail: Jean.Seguin@UMontreal.CA). on one cognitive domain called executive function (Barkley, 1997; Pennington \& Ozonoff, 1996; Zelazo, Carter, Reznick, \& Frye, 1997). In general, current definitions of executive functions comprise those abilities implicated in goal-oriented processes such as the initiation and maintenance of efficient strategies (Lezak, 1985), and the programming and planning of motor behaviour skills. They also encompass learning and applying contingency rules, abstract reasoning, problem solving, sustained attention, and concentration. Executive functions (1) require effort and active "on-line" 
monitoring resources in contrast with automatic processing, are called (2) particularly to process novel information (Zelazo et al., 1997) or (3) when high demands for cognitive resources are solicited (Stuss, 1992), and (4) operate in a limited-capacity system (Welsh \& Pennington, 1988). They are largely but not exclusively associated with the frontal lobes (Pennington \& Ozonoff, 1996; Stuss, 1992).

An earlier report (see Séguin, Pihl, Harden, Tremblay, \& Boulerice, 1995) concluded that in the context of a large number of cognitive-neuropsychological domains, executive functions were particularly impaired in boys with a history of physical aggression more than any other group of abilities. This conclusion raised an important question regarding the issue of specificity of executive function impairment in psychopathology; it was not clear if the relation between poor executive function and a history of physical aggression could have been mediated by the presence of Attention Deficit Hyperactivity Disorder (ADHD) (Pennington \& Ozonoff, 1996). Physical aggression is a diagnostic symptom of Conduct Disorder (CD) and an associated feature of ADHD. Further, CD and ADHD are often reported in the same individuals and have both been established as risk factors for alcoholism, most likely via a history of physical aggression (Pihl \& Peterson, 1991). With regard to executive functions, Pennington and Ozonoff (1996) concluded that impairments in executive functions are found in ADHD and autism and that the evidence for poor executive function involvement in $\mathrm{CD}$ without ADHD was weak. Further, when studies of $\mathrm{CD}$ do report executive function deficits, it is unclear whether ADHD may still be confounding the results or not. One recent study showed an association between aggressive $C D$ in women and poor executive function even after controlling for ADHD (Giancola, Mezzich, \& Tarter, 1998). However, the authors did not control for nonexecutive processes that may affect executive function tasks. The importance of examining the role of ADHD in any analysis of executive functions in externalising disorders is also brought to the forefront by other current theoretical work. For example, Barkley (1997) recently developed a theory of the hyperactive-impulsive type of ADHD in which he attributes a prominent role to poor executive functions and behavioural inhibition. Since none of the studies reviewed by Pennington and Ozonoff (1996) (including our earlier report) supported an unequivocal conclusion about the executive function/CD association when $\mathrm{CD}$ was not comorbid with ADHD, we have sought to control for ADHD in this study of executive functions and physical aggression. Thus our first question examines the robustness of the executive function/physical aggression relationship while controlling for ADHD.

It has become clear that there are several aspects to executive functions and various models use different categories to account for these. For example, they have been classified into categories such as set-shifting, planning, working memory, contextual memory, inhibition, and fluency (Pennington \& Ozonoff, 1996). Using a problem-solving framework, the executive function has been categorised in temporally ordered subphases such as (1) problem representation, (2) planning, (3) execution (including both intending and rule use), and (4) evaluation (including both error detection and error correction) (Zelazo et al., 1997). In another framework, they have also been grouped into categories that include working memory, self-regulation of affect-motivationarousal, internalisation of speech, and behavioural analysis-synthesis (Barkley, 1997). Using the frontal lobe metaphor, one particular subgroup of functions involved in working memory has been associated with dorsolateral frontal lobe activity (Petrides, Alivisatos, Evans, \& Meyer, 1993a). Within the dorsolateral frontal lobe there are two dissociable areas, the posterior and middorsolateral areas (Petrides et al., 1993a). The posterior dorsolateral front lobe appears to be specifically involved in conditional association tasks, whereas the middorsolateral frontal lobe would be involved in tasks of subjective ordering (Petrides et al., 1993a).

A number of studies suggest that performance of physically aggressive individuals may differ on tests representing these two domains of functions. Giancola's (1995) review suggests that poor Conditional Association abilities, but not Subjective Ordering abilities, are involved in laboratory aggression in normal males. One study by Giancola and Zeichner (1994) found that laboratory aggression (shock intensity and duration in response to provocation) was related to poor performance on the Spatial Conditional Association test; (SCA; Petrides, 1985), but not on the Self-Ordered Pointing test; (SOP; subjective ordering, Petrides \& Milner, 1982). This latter result appeared as a surprise to the authors and they speculated that it might be an artefact of the high level of education of their participants. In a similar study by Lau, Pihl, and Peterson (1995), groups were divided into upper and lower quartiles on a composite score constructed from tests of conditional association and subjective ordering. Levels of laboratory aggression (shock intensity to provocation) were higher in participants with poorer executive functions. However, the composite score was made of two variables extracted from the SCA and the SOP. It is likely that the SCA contributed more than the SOP to the composite by inflating the correlation of SCA performance to the composite (Tabachnick \& Fidell, 1989), a correlation that the authors did not report. We also reported findings implicating a composite score including Subjective Ordering and Conditional Association Learning tests, and its negative association with a childhood history of physical aggression (Séguin et al., 1995). In that study, the highest loading was for a test of Non-Spatial Conditional Association (NSCA; Petrides, 1985, 1990), although the loadings for two different subjective ordering tests (the SOP and a number randomisation task) were also above .50. The NSCA is related to, but slightly different from, the SCA used in the above-mentioned studies. Composite scores, useful as they may be, do not allow an assessment of the tests' discriminant ability. It is thus possible that the two executive function domains are not equally associated with physical aggression. Following Giancola's conclusion it would seem that performance on Conditional Association Learning tests might have more relevance to laboratory and physical aggression than performance on Subjective Ordering tests. This comparison constitutes our second question. 
In order to proceed with both questions, thorough examination of executive functions requires essential controls for cognitive abilities that may affect them (Pennington \& Ozonoff, 1996; Zelazo et al., 1997). Using the frontal lobe metaphor, this issue addresses the role of nonfrontal functions on measures of frontal executive function. Theoretically, in order to conclude that a group of individuals is impaired in working memory (i.e. more specifically dorsolateral frontal lobe), one has to ensure that variations in General Memory functions (i.e. those often associated with the hippocampi and medial temporal lobe) have been controlled (Petrides, 1995). The model developed by Milner and Petrides postulates that impairments in General Memory will necessarily affect executive function (Luria \& Homskaya, 1964; Petrides \& Milner, 1982), at least in individuals with lesions. This neuropsychological point of view speaks directly to two issues: (1) pre-frontal functions are affected by brain changes in regions outside but closely connected to the pre-frontal cortex (Petrides, 1995), and (2) nonexecutive components are involved in executive function tasks (Pennington \& Ozonoff, 1996). This important notion is similar to a methodological dissociation relevant to the assessment of working memory functions as outlined by Barkley (1997). This requirement specifies that the involvement of poor executive functions must be assessed in the context of proper information storage (knowledge). Problems should only be found in information manipulation and organisation over time (see also Delis, Squire, Bihrle, \& Massman, 1992; Stuss \& Benson, 1986; Zelazo et al., 1997). Finally, from a psychological point of view, this speaks to characteristics of complex functions that are inherently hierarchical in nature (Zelazo et al., 1997). First, there may be a hierarchy within the executive function domain and, second, there are no executive function tasks exclusively sensitive to variations in executive function or that are not "contaminated" by non-executive-function processes (Zelazo et al., 1997).

Aside from General Memory abilities, another nonexecutive component involved in executive function tasks may be IQ. There is overlap between IQ and executive functions and one would not want to conclude that poor executive function is a characteristic of behaviour problems without ensuring that intelligence is not confounding the results. Although intelligence is often reported as being independent of executive function (Milner \& Petrides, 1984), the capacity for readily understanding and remembering the fairly complex rules involved in some tests could presumably be affected by poor intelligence. Intelligence, in addition to affecting executive function, may mediate aggressive behaviour. Indeed, intelligence is considered to be a protective factor against the development of delinquency and criminality (Kandel et al., 1988; Lynam, Moffitt, \& StouthamerLoeber, 1993; White, Moffitt, \& Silva, 1989). A control for IQ in the current study is even more important in light of the studies of the role of the dorsolateral frontal lobe and laboratory aggression reviewed above. Indeed, the groups with high and low executive functions formed by Lau et al. (1995) differed not only in laboratory aggression but also in IQ. Thus it is not clear whether IQ confounded the significant executive function/aggression relationship they reported. On the other hand, Giancola and Zeichner (1994) did control for IQ. It is possible that the influence of IQ in their analyses may also have been minimised by their high average levels of education (mean $=16.1$ years, $S D=1.9)$ and of IQ $($ mean $=110.5$, $S D=11.1)$. This suggests a problem of range. The role of IQ in the low SES community sample we propose to examine may be more important for the executive function/physical aggression relationship, which may be mediated, if not explained, by IQ.

In sum, we examined if poor performance on tests of executive functions remained a feature of physical aggression once ADHD status, General Memory abilities, and intelligence were controlled. We expected that a history of physical aggression would be characterised more by poorer performance on conditional association tests than on subjective ordering tests. To answer these questions, data on an additional conditional association test for working memory, on intelligence, and on adolescence psychiatric diagnoses were collected on most of the participants that were the object of our initial report (Séguin et al., 1995) in the 2 years that followed. We added previously collected data on General Memory abilities and executive function to complete our model.

\section{Method}

Initial selection of participants and complete details regarding portions of the cognitive-neuropsychological test battery have been published elsewhere (see Séguin et al., 1995), and will be summarised where relevant.

\section{Participants}

Participants were obtained from a large low socioeconomic status community sample of 1037 boys that has been followed longitudinally since kindergarten. Teacher ratings of aggressive behaviour at ages $6,10,11$, and 12 (i.e. fights with other children, kicks, bites and hits other children, and bullies or intimidates other children; alpha $=.86$; Tremblay et al., 1991) were used to form three nonoverlapping categories of boys who differed in stability and severity of physically aggressive behaviour. The Stable Aggressive group was composed of those boys who were rated consistently high in their aggression at age 6 and later (cutoff for the scale score at the 70th percentile). Those who were consistently below the cutoff point over the same period formed a Nonaggressive group. The overwhelming majority of Nonaggressive boys had a score of 0 across all assessment points. Finally, those who did not meet the criteria above and who were occasionally highly aggressive (at one or two measurement points) formed an Unstable Aggressive group $^{1}$. In our initial report 177 boys came at both ages 13 and

\footnotetext{
1 A similar approach to classification was performed on another dimension: negative emotionality. Efforts had been made at the time to recruit participants who would show high levels of aggression but low levels of negative emotionality in order to identify individuals who would show characteristics of lowanxious psychopaths. This purpose was independent of the current study. Although there are too few such individuals to perform statistical analyses, the sampling procedure resulted in a change of the bivariate relation between physical aggression and negative emotionality in the laboratory sample as compared to the large sample. This effect was controlled.
} 
14 (Séguin et al., 1995). At age 15, 161 of them returned to our laboratory for more cognitive-neuropsychological testing and other scientific activities.

\section{Measures}

Cognitive-neuropsychological function. The test battery included the Digit Span and Paired Associates subtests from the Wechsler Memory Scales-Revised (Wechsler, 1987), three frontal lobe tests validated by lesion and brain imaging studies, the NSCA (posterior dorsolateral) and SOP (subjective ordering, mid-dorsolateral) tasks (Petrides et al., 1993a), and the number randomisation (Petrides, Alivisatos, Meyer, \& Evans, 1993b) (a.k.a. subjective ordering; mid-dorsolateral; Wiegersma, van der Scheer, \& Human, 1990). This portion of the battery was administered over two laboratory visits 1 year apart (ages 13 and 14). These tests were included in two factors defined by items loading above .50 and had been derived from a larger cognitive-neuropsychological battery of tests after oblique rotation (Séguin et al., 1995). For this study we retained elements of two factors representing verbal learning (Digit Span, Paired Associates, respective loadings .55 and .55), and executive functions (NSCA, SOP, and number randomisation, respective loadings $.82, .55$, and .69). Digit Span and Paired Associates theoretically assess General Memory processes such as those subsumed by the hippocampus and medial temporal lobe (see Petrides, Alivisatos, \& Evans, 1995; Squire \& ZolaMorgan, 1991).

For the age 15 laboratory visit we collected the SCA task (posterior dorsolateral frontal lobe; Petrides, 1985) that was used in Giancola and Zeichner (1994) and Lau et al. (1995). We also collected IQ estimates derived from the Vocabulary and Block Design subtests of the Wechsler Intelligence Scale for Children-Revised (WISC-R; Wechsler, 1974). The combination of these subtests correlates positively at more than .90 with Full Scale IQ (Sattler, 1988). Although the measure of IQ was not administered concurrently with the bulk of the cognitiveneuropsychological assessment, its score should be reliable since IQ is relatively stable across time. We will verify this claim with the use of IQ estimates collected on a subsample of these boys at ages 10,11 , and 12 .

Task instructions are summarised as follows. The Digit Span involves repeating digits in increasing spans in forward and backward orders (Wechsler, 1987). The Paired Associates requires listening to pairs of easy or difficult words. The first word of the pair is then given in order to prime recall of the second word of the pair (Wechsler, 1987). In the number randomisation task a range of numbers is provided (e.g. from 1 to 10) (Séguin et al., 1995). All numbers in the range must then be selected without repetition and without any apparent pattern. The SOP consists of two sets (one abstract and one concrete) of 12 arrays of the same 12 stimuli (Milner, Petrides, \& Smith, 1985). The position of the stimuli changes from one array to the next and subjects must select a different stimulus on each array. Repetitions are counted as errors. In conditional association learning tasks one must uncover six pairs of stimuli. In the NSCA, six hand signals are initially taught (Petrides, 1990). Then six colours are presented in a predetermined random order, one at a time, until correct identification of the colourhand signal combination is achieved. For the SCA, six abstract symbols need to be paired with small lights in six locations (Petrides, 1985). Instead of colours, abstract symbols are presented one at a time. In both cases, trials are repeated until a criterion of 18 consecutive errorless trials is met. The Vocabulary subtest of the WISC-R requires the definition of words of gradually increasing difficulty (Wechsler, 1974). Similarly, for the Block Design subtest of the WISC-R, subjects must reproduce two-dimensional patterns of red and white colours with four or nine red and white blocks (Wechsler, 1974).
Psychiatric status. The Diagnostic Interview Schedule for Children (DISC) was used to obtain childhood psychiatric diagnoses (Costello, Edelbrock, \& Costello, 1985). The DISC is an assessment tool based on the Diagnostic and statistical manual of mental disorders from the American Psychiatric Association. The version employed in this study was based on DSM-III-R criteria (American Psychiatric Association, 1987), and is a French adaptation of the DISC 2.25 using child (-C) and parent (-P) forms (Valla et al., 1994). In its original form, the DISC-P is thought to be more sensitive than the DISC-C for several disorders (Fisher et al., 1993). Test-retest reliability of the DISC 2.1 was moderate (i.e. CD, oppositional defiant disorder [ODD]) to substantial (i.e. for ADHD), and found to be best using a combination of both child and parent reports (Jensen et al., 1995). More specifically, DISC-P reliability was good to excellent for ADHD and fair for other externalising disorders with children aged 6-11, whereas it was poor for other disorders using the DISC-Revised version (Schwab-Stone, Fallon, Briggs, \& Crowther, 1994). The relative validity of the parent or child versions is not well known, but the combination of parent and child reports would better approximate clinical practice (Jensen et al., 1995).

Using symptom scores from our larger sample, reliabilities for the child and parent as informants were respectively .88 and .92 for ADHD. Spearman correlations for the child and parent as informants were respectively of .42 and .43 for ADHD and ODD and .32 and .34 for ADHD and CD. Correlations between ADHD and internalising disorders were all below .10 for both informants. Results of a large random survey of children aged 6 to 14 years old and using both the French and English versions of the DISC 2.25 were published in an official report (Valla et al., 1994). In that report, issues of validation were investigated and revealed a small degree of methodological problems that hardly affected factual data. However, overall between-informant agreement was low and, specifically, teacher-parent agreement were higher than child-parent or child-teacher agreements. These results nevertheless remain consistent with those of several other studies (Achenbach, McConaughy, \& Howell, 1987; Offord, Boyle, \& Racine, 1989). Specifically, and as expected, externalising disorders were more prevalent in boys and internalising disorders were more prevalent in girls (Valla et al., 1994). For example the prevalence rate for ADHD in boys 9-11 years of age and 12-14 years of age were respectively $6.9 \%$ and $2.8 \%$ by child report, $7.3 \%$ and $5.1 \%$ by parent report, and $13.2 \%$ for age 9-11 by teacher report. The boys' prevalence rate for $\mathrm{CD}$ was around $3 \%$ for child report between ages 9-14. Children with mental health problems tended to have parents with such problems as well, their parents' discipline style tended to be punitive, and they had higher familial adversity. Poor social competence and low father education were associated with externalising disorders. In contrast to other epidemiological studies of the kind, academic problems seemed to be exclusively associated with externalising disorders.

\section{Procedure}

The DISC 2.25 data were collected from ages 14 to 16 . Briefly, a letter followed up by telephone contacts served to solicit participation. After setting an appointment, two trained interviewers visited the boy's residence in order to obtain information simultaneously from both informants individually (the boy and one guardian, mainly the mother). The interview lasted between 1 and $1 \frac{1}{2}$ hours and was given in paper-pencil form. DISC scores were obtained for 739 boys from the large longitudinal sample. From the laboratory sample of 161 , ADHD data by either informant were available for 152 of them.

The cognitive neuropsychological test battery was administered over three visits to the laboratory at ages 13,14 , 
and 15. Specifics for the age 13 and 14 assessments have been the object of a previous report (Séguin et al., 1995). At age 15, the IQ assessment was administered following the regular procedure for WISC-R Vocabulary and Block Design subtests. The full IQ score estimate was obtained following Wechsler's (1987) instructions. The SCA test was administered during that same laboratory visit.

ADHD, IQ, SCA and other cognitive-neuropsychological data were available for 149 of the 161 participants. Analyses were carried out on SPSS version 4.0 for UNIX.

\section{Data Preparation}

No multivariate outliers could be identified (Tabachnick \& Fidell, 1989). In order to meet statistical assumptions of normality and homogeneity of variance, data for the SOP errors received square-root and reciprocal transformations, data for both the NSCA and SCA received square root transformation, and a few outliers (three for NSCA and six for SCA) were moved into the distribution next to the highest nonoutlying value while respecting their ranking, data for Paired Associates received logarithmic and reciprocal transformations, and negative emotionality received a square root transformation (Tabachnick \& Fidell). Signs for SOP, NSCA, and SCA were changed to reflect better performance with higher scores. Test scores of SOP abstract and concrete errors, and number randomisation number of successes, were standardised and averaged to form one composite score of Subjective Ordering. This procedure was repeated with NSCA trials with errors, and SCA trials with errors to form the Conditional Association Learning composite score. Digit Span and Paired Associates easy and difficult correct responses were standardised and averaged to produce a General Memory control. Examination of the variables revealed normal distributions within the groups as measured by skewness and kurtosis following transformations (Tabachnick \& Fidell).

\section{ADHD Status}

ADHD status using combined parent and child report can be obtained in several ways. We have chosen to attribute this status to boys who met diagnostic criteria based on parent or child report. In the laboratory sample $(N=149)$, there were a total of 19 participants $(12.8 \%$ of the laboratory sample) who met diagnostic criteria of ADHD by either parent or self-report. None of the self-diagnoses and parent diagnoses of ADHD coincided. Missing data within this sample's ADHD diagnoses were found for seven parent reports. Two of them met diagnostic criteria according to self-reports. Breakdown by groups for the participants who received a diagnosis of ADHD was 10 Stable Aggressive, 8 Unstable Aggressive, 1 Nonaggressive. Thus, $95 \%$ of ADHD participants were classified as aggressive in one form or another.

Given the lack of overlap between informants (self- and parent) regarding the ADHD diagnosis in the laboratory sample, we examined the overlap in the larger sample for ADHD symptoms. In the larger sample, ADHD diagnoses using self-report or parent report could be established for 749 boys. Thus 78 boys met criteria for an ADHD diagnosis, representing $12 \%$ of that sample. Boys classified as either Stable or Unstable Aggressive accounted for $92.3 \%$ of ADHD boys. Thus the proportion of ADHD cases in the laboratory sample cannot be attributed to the selection of the subsample from the large one. Overall, parents $(N=54)$ more than children $(N=$ $20)$ reported ADHD symptoms in the large sample; four cases met diagnostic criteria by both informants. Within those boys who met diagnostic criteria by either parent or child report, between-informant average agreement across the 14 symptoms regarding (a) presence of symptoms was $18.8 \%$, (b) absence of symptoms was $23.7 \%$, (c) symptom(s) identified by parent only was $46.5 \%$, and (d) symptom(s) identified by boy only was $11 \%$. Thus, the agreement concerning the presence of symptoms is much more important than it appears to be when presenting ADHD diagnoses.

\section{Negative Emotionality}

Teacher-rated negative emotionality was used as another covariate since it had been a criterion for the selection of the laboratory sample for reasons that were not the object of this study.

\section{Results}

\section{IQ Stability}

We predicted earlier that IQ at age 15 could serve as a reliable control for neuropsychological test performance collected at ages 13 and 14. Although we had not collected IQ estimates at those ages, we were able to examine IQ stability over time in a subsample of these boys. The same IQ estimates had been collected at ages 10,11, and 12 in other components of this longitudinal study. An average of those 3 years' data collection correlated at .92 with age $15 \mathrm{IQ}$.

\section{Physical Aggression and Executive Functions}

The main questions involved a control for ADHD, IQ, and General Memory. These variables were entered as covariates in a MANCOVA comparing the three groups (independent variable) on the two executive function composite scores (dependent variables). ADHD status was entered as a dummy variable. We also controlled for teacher-rated negative emotionality. Pearson correlations of cognitive neuropsychological variables and composite scores prior to the analyses are presented in Table 1 for descriptive purposes. Table 1 also includes Spearman correlations for ADHD status and number of symptoms with the cognitive neuropsychological variables. An examination of Table 1 reveals a nonsignificant correlation between the two Subjective Ordering tests, and a high correlation between the two Conditional Association Learning tests. The two composite scores were also moderately correlated with each other and with the General Memory composite and IQ. Since tests included in the composite scores were averaged, this attributed them equal weights as indicated by the fact they correlate equally with the composite score. The correlations between ADHD and the cognitive tests were only significant for number of ADHD symptoms with IQ, the General Memory composite, and the Paired Associates learning test. These latter correlations were negative, as expected.

The MANCOVA was then performed on 149 cases: 57 in the Stable Aggressive group, 45 in the Unstable Aggressive group, and 47 in the Nonaggressive group. The initial step consisted of verifying the general assumptions for the model. This examination revealed significant heteroscedasticity of the variance/covariance matrix across aggression groups. We postulated that this phenomenon could be due to differential effects of the covariates between the aggression groups (i.e. interactions). The first covariate to be examined was ADHD. 
Table 1

Correlations among Cognitive-neuropsychological Tests and ADHD Prior to MANCOVA $(N=149)$

\begin{tabular}{|c|c|c|c|c|c|c|c|c|c|c|c|}
\hline & NR & SOP & SOc & NSP & SPA & $\mathrm{CAc}$ & DSPAN & PASS & MEM & IQ-ES & ADHD \\
\hline SOP & .15 & & & & & & & & & & \\
\hline $\mathrm{SOc}$ & $.76^{* * *}$ & $.76^{* * *}$ & & & & & & & & & \\
\hline NSP & $.32 * * *$ & $.36^{* * *}$ & $.45 * * *$ & & & & & & & & \\
\hline SPA & $.22 * * *$ & $.21^{*}$ & $.28 * * *$ & $.48 * * *$ & & & & & & & \\
\hline CAc & $.32 * * *$ & $.33 * * *$ & $.42 * * *$ & $.86^{* * *}$ & $.86^{* * * *}$ & & & & & & \\
\hline DSPAN & $.35 * * *$ & $.17^{*}$ & $.34 * * *$ & $.41 * * *$ & $.38 * * *$ & $.46^{* * * *}$ & & & & & \\
\hline PASS & $.22 * *$ & .15 & $.24 * *$ & $.24 * *$ & $.32 * * *$ & $.33 * * *$ & $.32 * * *$ & & & & \\
\hline MEM & $.35 * * *$ & $.20 *$ & $.36 * * *$ & $.41 * * *$ & $.43 * * *$ & $.49 * * *$ & $.81 * * *$ & $.82 * * *$ & & & \\
\hline IQ-ES & $.30 * * *$ & $.33 * * *$ & $.42 * * *$ & $.32 * * *$ & $.29 * * *$ & $.35 * * *$ & $.40 * * *$ & $.36 * * *$ & $.47 * * *$ & & \\
\hline ADHD & -.09 & -.06 & -.10 & .04 & .03 & .05 & -.04 & -.12 & -.07 & -.09 & \\
\hline ADHDS & -.11 & -.06 & -.12 & -.03 & .03 & -.01 & -.09 & $-.15^{*}$ & $-.16^{*}$ & $-.26^{* * *}$ & $.56^{* * *}$ \\
\hline
\end{tabular}

ADHD: Attention Deficit Hyperactivity Disorder; ADHDS: ADHD symptom count; CAc: Conditional Association composite; DSPAN: Digit Span; IQ-ES: Intelligence Quotient Estimate; MEM: General Memory; NR: Number Randomization; NSP: NonSpatial Conditional Association; PASS: Paired Associates; SPS: Spatial Conditional Association; SOc: Subjective Ordering composite; SOP : Self-Ordered Pointing.

$* * * p \leqslant .001 ; * * p \leqslant .01 ; * p \leqslant .05$

Table 2

Multivariate Statistics for Interactions and Main Effects on Subjective Ordering and Conditional Association Learning Composite Scores

\begin{tabular}{lcccccc}
\hline Effect & \multicolumn{1}{c}{$T^{\mathrm{a}}$} & \multicolumn{1}{c}{$F$} & $d f$ & $p$ & Power & $\begin{array}{c}\text { Effect } \\
\text { size }\end{array}$ \\
\hline General memory by groups & .130 & 4.35 & 4,272 & .002 & .93 & .060 \\
General memory & .170 & 11.65 & 2,137 & .001 & .99 & .150 \\
IQ by groups & .110 & 3.64 & 4,272 & .007 & .87 & .050 \\
IQ & .110 & 7.52 & 2,137 & .001 & .94 & .100 \\
Groups & .120 & 4.21 & 4,272 & .003 & .92 & .060 \\
Negative emotionality & .003 & 0.20 & 2,137 & .823 & .08 & .002 \\
ADHD status & .020 & 1.06 & 2,137 & .350 & .23 & .020 \\
\hline
\end{tabular}

${ }^{\text {a }}$ Hotellings.

Table 3

Univariate F Statistics for Subjective Ordering and Conditional Association Composite Scores

\begin{tabular}{|c|c|c|c|c|c|c|c|c|c|c|}
\hline \multirow[b]{2}{*}{ Effect } & \multicolumn{5}{|c|}{ Subjective Ordering } & \multicolumn{5}{|c|}{ Conditional Association } \\
\hline & $F$ & $d f$ & $p$ & Power & $\eta^{2 \mathrm{a}}$ & $F$ & $d f$ & $p$ & Power & $\eta^{2 \mathrm{a}}$ \\
\hline General memory by groups & 6.93 & 2,138 & .001 & .92 & .09 & 3.07 & 2,138 & .050 & .58 & .040 \\
\hline General memory & 3.04 & 1,138 & .084 & .41 & .02 & 23.16 & 1,138 & $<.001$ & .99 & .140 \\
\hline IQ by groups & 7.36 & 2,138 & .001 & .94 & .09 & 0.30 & 2,138 & .744 & .10 & .004 \\
\hline IQ & 13.59 & 1,138 & $<.001$ & .96 & .09 & 3.82 & 1,138 & .053 & .49 & .030 \\
\hline Groups & 4.19 & 2,138 & .017 & .73 & .06 & 3.90 & 2,138 & .022 & .70 & .050 \\
\hline
\end{tabular}

${ }^{\text {a }} \eta^{2}$ (eta square) was used by SPSS to calculate the effect size.

However, the very low number of ADHD participants in the nonaggressive group precluded direct verification of the interaction term. Instead, we removed ADHD from the model and observed that this did not resolve the heteroscedasticity problem. A finer examination of the correlations between number of ADHD symptoms and the dependent variables in the groups revealed nonsignificant correlations. We then reintroduced ADHD in the model and examined if the assumption of homogeneity of regression slopes (i.e. interactions) for negative emotionality, IQ, and General Memory was met (Tabachnick \& Fidell, 1989). The interaction for negative emotionality and groups was nonsignificant and removed from the model. The two remaining interactions were significant but only for the Subjective Ordering composite score. The effect for the Conditional Association Learning composite approached significance with a criterion set at $p<.05$ and power was low. The main effect for the Conditional Association Learning composite score was significant while those for teacher-rated negative emotionality and ADHD status were not. Hotellings $T$ and $F$ statistics for the multivariate effects are presented in Table 2 for main effects and interactions. Corresponding univariate statistics for Subjective Ordering and Conditional Association Learning composite scores are presented in Table 3. Results for Conditional Association Learning test scores will be presented first followed by those for Subjective Ordering test scores. 
Table 4

Means and Standard Errors for Cognitive-neuropsychological Variables per Group

\begin{tabular}{|c|c|c|c|c|c|c|}
\hline & & & & & & \\
\hline & $\begin{array}{r}\mathrm{Sg} \\
\mathrm{Ag}\end{array}$ & & & & Non & sive \\
\hline & Mean & $S E$ & Mean & $S E$ & Mean & $S E$ \\
\hline gMEM $^{\mathrm{a}}$ & -0.13 & 0.11 & -0.01 & 0.12 & 0.17 & 0.12 \\
\hline $\mathrm{IQ}-\mathrm{ES}^{\mathrm{a}}$ & 96.02 & 1.43 & 100.33 & 1.56 & 106.02 & 1.63 \\
\hline $\mathrm{zCA}$ & -0.02 & 0.10 & -0.25 & 0.15 & 0.27 & 0.11 \\
\hline $\mathrm{azCA}^{\mathrm{ab}}$ & 0.10 & 0.12 & -0.27 & 0.13 & 0.13 & 0.16 \\
\hline zSO & -0.28 & 0.08 & -0.05 & 0.12 & 0.38 & 0.10 \\
\hline $\mathrm{azSO}^{\mathrm{ab}}$ & -0.19 & 0.10 & -0.01 & 0.11 & 0.24 & 0.14 \\
\hline
\end{tabular}

azSO: final adjusted standardised Subjective Ordering composite score; azCA: final adjusted standardised posterior Conditional Association score; gMEM: General Memory; IQ-ES: Intelligence Quotient estimate; zSO: nonadjusted standardised Subjective Ordering composite score; zCA: nonadjusted standardised Conditional Association composite score.

a Means adjusted for the covariates negative emotionality and ADHD status.

${ }^{\mathrm{b}}$ Means also adjusted for General Memory and IQ.

Conditional Association Learning test score main effect. Since there were no interactions with the Conditional Association Learning composite score, the main effects reported in Table 3 may be considered for that variable. The effect of aggressive groups on the Conditional Association Learning score was significant. Table 3 indicates that General Memory brought significant correction to the Conditional Association Learning composite score whereas IQ did not. Means and standard errors for all the cognitive-neuropsychological variables are presented in Table 4 . The effects of the covariates on the group means can be examined in Table 4 by comparing nonadjusted to adjusted means for the executive function test scores. Planned contrasts for the main effect of aggressive groups revealed differences between the Stable Aggressive and Unstable Aggressive groups, $t(100)=-2.41, p<.02$, and between the Unstable Aggressive and Nonaggressive groups, $t(90)=2.34, p=$ .02. This indicates that performance on the Conditional Association Learning composite score was significantly lower for the Unstable Aggressive group.

Subjective Ordering test score interactions. In contrast to the Conditional Association Learning test score, the adjusted means and standard errors for the Subjective Ordering score were ordered by level of aggression with the Stable Aggressive group showing the poorest performance. However, in MANOVA interactions preclude any straightforward conclusion from the significant main effect. In examining both interactions, we also verified if these have not been caused by different ranges in the aggression groups, ruling out the possibility of confound between aggression groups and the covariate in their relationship to the Subjective Ordering score.

General Memory and aggressive groups interaction. This interaction for the Subjective Ordering composite indicates that the regression slopes for both aggressive groups do not differ significantly though they differ significantly for the Unstable Aggressive and Nonaggressive groups (parameter coefficient $-0.57, S E=$ $0.19, t=-3.02, p<.003)$. In other words, we found that an increment of General Memory that is associated with an increase on the Subjective Ordering composite of 0.57 $S D$ in the Unstable Aggressive group will be associated with no increase in the Nonaggressive group. In fact there is no relation between General Memory and the Subjective Ordering composite score in the nonaggressive groups. No range problems were observed.

$I Q$ and aggressive groups interaction. In contrast to General Memory, this interaction for the Subjective Ordering composite indicates that the slopes differed for the aggressive groups (parameter coefficient $0.44, S E=$ $0.15, t=2.92, p<.004$ ). In other words, the increment of IQ score that is associated with an increase of $1 S D$ in the Stable Aggressive group is associated with an increase of $1.44 S D$ in the Unstable Aggressive group. However, as opposed to General Memory, boxplots indicated that the ranges of IQ in the three groups show important problems in overlap and in skewness. Therefore, teasing the effects of aggression groups apart from IQ in their relation with the Subjective Ordering composite is seriously compromised.

Interactions conclusion. In sum, the first interaction indicates that, overall, the Nonaggressive group's performance is not as impaired as that of both aggressive groups at lower levels of General Memory. The second interaction indicates that higher IQ scores do not provide the advantage to the Stable Aggressive group that it does for the two other groups.

\section{Discussion}

\section{Specificity of Executive Function Test Performance to Physical Aggression vs. ADHD}

It is clear that in the current sample ADHD does not account in any way for the observed association between executive functions and a history of physical aggression. Although ADHD was strongly associated with a history of physical aggression, it was not associated at all with poor executive functions as the literature generally seems to indicate (Barkley, 1997; Pennington \& Ozonoff, 1996). Several factors may account for these observations in this sample. 
First, we chose to control for ADHD by using a composite of child and informant diagnoses. Diagnostic criteria were established separately within each informant then combined. This method has limitations. Two other methods have been used as well. One of them consists of combining child and informant reports at the symptom level (Jensen et al., 1995; Schwab-Stone et al., 1993). In this situation, a symptom is given a 1 if the child or the informant has reported it. Symptoms are then added from this list to form a total symptom score. The total symptom score can then be used by itself or following the DSM diagnostic criteria. In the latter situation a positive diagnosis is determined when the combined informant symptom count reaches the symptom count criterion. We did examine the effect of both approaches in our analyses. Whether we used one or the other method, our results were essentially the same as those already reported. Interestingly, the second diagnostic approach increased the number of positive diagnoses by nine in the aggressive groups only. Nonetheless, the ADHD symptom count was negatively associated with IQ and General Memory scores. This indicates sensitivity of non-executive function cognitive abilities to ADHD as measured in this sample.

Second, there may be differences between clinical and community samples. Our results are consistent with those of a study by McGee, Williams, Moffitt, and Anderson (1989), who failed to find executive function deficits in ADD-H in a community sample. However, the comparison with that study remains limited as ADD-H as well as the neuropsychological assessments were different and many of our non-ADHD participants could not really qualify as controls since they had other behaviour problems. Nonetheless, it is possible that ADHD and poor neuropsychological function are more strongly associated in referred samples (Pennington \& Ozonoff, 1996). Further, test-retest reliabilities of diagnostic instruments used in community vs. clinical settings tend to be poorer in the former (Jensen et al., 1995). Third, there is a possibility that our measures of executive functions are different from most measures employed in studies of ADHD. Since there are many subdomains of EFs, even within working memory, as we have shown here, this could be a reasonable hypothesis. A fourth possibility is that our measure of ADHD is inappropriate. We are aware of the controversies surrounding the use of the DISC (see Hodges, 1993; Roberts, Solovitz, Chen, \& Casat, 1996; Shaffer, 1994). Although far from perfect, version 2.25 represented improvements over earlier ones. Nonetheless, the sensitivity of the DISC 2.25 in childhood has been questioned. It was found that less than half of 9-11-year-old children really understood the interview questions (Breton et al., 1995; SchwabStone, 1995). However, we administered the DISC to boys age 14-16, where this problem is less of an issue (Edelbrock, Costello, Dulcan, Kalas, \& Conover, 1985). Further, and as indicated earlier, total number of ADHD symptoms did correlate negatively with General Memory and IQ, and ADHD status was reported specifically in aggressive groups. A fifth possibility has to do with the fact that our assessment of ADHD took place in adolescence rather than in childhood. This methodological point, though, should facilitate the detection of boys whose hyperactivity is truly chronic since ADHD tends to be of early onset and stable (Biederman et al., 1996). Further, ADHD appears to show the same pattern whether it is assessed in childhood or adolescence (Biederman et al., 1998). However, we did not benefit from a full prospective history of ADHD in the participants from this study.

\section{The Dorsolateral Perspective on Executive Functions and Physical Aggression}

In this study executive functions were defined from a neuropsychological perspective as performance on tests theoretically assessing dissociable functions that correspond to the mid-dorsolateral and posterior dorsolateral frontal lobe (Petrides et al., 1993a). The respective abilities subsumed by these areas are Subjective Ordering and Conditional Association Learning. Unlike a previously reported finding that indicated poorer performance in Stable and Unstable Aggressive groups than in a Nonaggressive group on a composite of Subjective Ordering and Conditional Association Learning test scores, disaggregating these scores allowed us to uncover two different patterns. The most straightforward pattern concerned Conditional Association Learning test performance. It is the Unstable Aggressive group that showed the poorest performance relative to the Stable and Nonaggressive groups. Although no specific contrast had been planned to examine the differences between Stable and Nonaggressive boys, an examination of adjusted means and standard errors in Table 4 seems consistent with the absence of differences between those two groups. The second pattern revealed a relationship between Subjective Ordering test performance and physical aggression that is not straightforward and requires finer examination.

The question examined the relationship between nonexecutive cognitive components and dorsolateral test scores within the groups. We found interactions between the Subjective Ordering composite score and the covariates General Memory and IQ and must exert caution in interpreting them. Statistically, the interactions indicate that the slopes describing the relationship for General Memory and IQ with the Subjective Ordering composite are not parallel. These interactions also mean that General Memory does not bring any correction to Subjective Ordering test performance in the Nonaggressive group and that IQ fails to correct the same scores in the Stable Aggressive group. From the point of view of psychopathology, it appears that the Stable Aggressive and Nonaggressive groups still differ. Not only are their means ordered in the direction previously reported, i.e. significantly better performance for Nonaggressive boys (Séguin et al., 1995), but their relationship with covariates seem consistent with that report. Specifically, the Nonaggressive group does not appear to be disadvantaged by lower General Memory abilities, and the Stable Aggressive group does not gain the advantage provided by higher IQ in the other groups.

Disaggregating the Subjective Ordering and Conditional Association Learning test scores supports the notion of involvement of poor executive function in boys with a history of physical aggression. The outcome of this 
process clearly indicates two profiles of executive functions. Poor Conditional Association Learning abilities may be characteristic of boys with an unstable history of physical aggression whereas poor Subjective Ordering abilities may better discriminate boys with a stable history of physical aggression from Nonaggressive boys. Thus Unstable Aggressive boys are most clearly impaired in cognitive functions that require learning new rules of association, whereas Stable Aggressive boys do not differ from Nonaggressive boys in these abilities once IQ and General Memory have been controlled for. Stable Aggressive boys, and Unstable Aggressive boys to a lesser extent, have difficulties in actively organising greater amounts of information in their environment by themselves than do Nonaggressive boys. Factors other than cognitive abilities may be invoked in explaining why variations in IQ in the Stable Aggressive group are not associated with variations in Subjective Ordering test scores, and why variations in General Memory are not associated with variations in Subjective Ordering test scores in Nonaggressive boys.

Our results may help clarify the apparent inconsistencies between studies of laboratory aggression that were reported by Giancola and Zeichner (1994) and Lau et al. (1995). Whereas these authors have examined the reactions to provocation of individuals classified on the basis of their EF test scores, we sought to examine the executive function test performance of boys with known histories of physically aggressive behaviour. Both laboratory aggression studies have used mid- and posterior dorsolateral tests but only Giancola and Zeichner looked at nonaggregated scores. Further, Lau et al. biased their composite executive function score by including two highly correlated measures of the same Conditional Association Learning test, i.e. total numbers of trials to criterion and number of incorrect guesses. Their composite score, which also included number of SOP errors, was therefore disproportionately representative of Conditional Association Learning test performance.

Giancola and Zeichner's (1994) finding that laboratory aggression was specifically related to poor Conditional Association Learning test performance and not to Subjective Ordering test performance may indicate that Unstable Aggressive boys have a history of aggression because they are more likely to be easily provoked. This is also consistent with the fact that these boys have a tendency to be more sensitive to pain (Séguin, Pihl, Boulerice, Tremblay, \& Harden, 1996), and have high levels of neuroticism, which may contribute to failures in self-regulation (Séguin, Arseneault, Boulerice, \& Tremblay, 1999). Increased sensitivity to pain would theoretically imply pain avoidance behaviour and therefore the avoidance of fights. However, poor performance on Conditional Association Learning tasks may indicate that these boys may not be very sophisticated when it comes to understanding the rules of novel situations, particularly those that may involve cues for provocation. They may thus get stuck in fight-flight types of situations for which they fail to see any escape (Gray, 1987). Alternatively, these boys may attribute hostile intent more readily by default because of their poor cognitive abilities at interpreting social cues. This individual characteristic may thus render them more reactively aggressive
(Dodge \& Coie, 1987; Dodge, Lochman, Harnish, Bates, $\&$ Pettit, 1997). In sum, the poor cognitive abilities and sensitivity to provocation could help explain the history of physical aggression and the pain sensitivity could explain the fact that their history of physical aggression is not consistent.

The relative proficiency of Stable Aggressive boys on Conditional Association Learning test performance may appear as a surprise. However, one must keep in mind that the similarity between Stable Aggressive and Nonaggressive boys only appears once the significant covariate effect of General Memory is taken into account. Without covariates, the Stable Aggressive group does not differ significantly from the Unstable Aggressive group in post hoc comparisons from one-way analyses of variance.

It is also important to state that our analysis does not necessarily imply neuropsychological dysfunction. Although the "frontal lobe metaphor" is a relevant heuristic, it has several limitations when tests purported to measure neuropsychological function are applied in developmental psychopathology (Spreen, Risser, \& Edgell, 1995). Some of these limitations are psychometric whereas others are theoretical. For example, from a purely neuropsychological point of view one would have expected a significant correlation between the two Subjective Ordering tests. That was not the case. However, both tests have been validated as mid-dorsolateral tests in two separate studies (Petrides et al., 1993a, b). One problem may be that we administered both tasks on two different visits. Although this methodological procedure did not seem to affect the two Conditional Association Learning tasks, it may have affected the Subjective Ordering tasks. The former tasks are also more similar in administration than the latter. It would be useful to have full validation studies using both tasks in a same sitting in order to strengthen the theoretical proposition. Further, we do not know much about the stability of cognitive abilities during adolescent development. While we have shown that IQ is relatively stable, little is known about the stability of executive functions. Nonetheless, our prior factor analysis indicated that both tests of Subjective Ordering loaded highly on the same executive function factor (Séguin et al., 1995).

Second, there may be conceptual questions regarding the use of IQ subtests to control for executive function. Performance on the Digit Span and Block Design subtests of the WISC-R as well as the Paired Associates test of the Wechsler Memory Scale may reflect some executive processing. However, from a neuropsychological perspective, circumscribed dorsolateral lesions should not affect the Digit Span (Petrides et al., 1995). Although this principle received support in lesion studies, it may not hold for nonlesioned individuals since reciprocal connections between otherwise dissociable brain areas remain intact. In fact the Digit Span and Paired Associates tests loaded respectively at .39 and .21 on the executive function factor in our former study (Séguin et al., 1995). This correlation may well be the fact that executive functions theoretically require abilities such as those involved in the Digit Span and Paired Associates tests. On the other hand, this could be interpreted in favour of conceptualising the Digit Span as an executive task. The backwards version of the Digit Span test requires indeed 
a little more on-line effort than its forward version, yet not as much as the number randomisation task. However, the Paired Associates Learning task requires remembering pairs of words in an immediate recall format, whereas an associational learning executive function task such as the Conditional Association Learning task requires figuring out the pairs of stimuli in a much longer trial and error process with feedback. The Digit Span and Paired Associates learning task are much more passive memory tasks than the executive function tasks presented here. With regards to the Block Design task, the conceptual overlap with executive functions can be seen in the requirements for planning, monitoring performance, and error detection and correction. However, the results of the performance do not need to be maintained and manipulated on-line since the participant may compare his or her construction with a model. Of the EF tasks, only the Conditional Association tasks have a feedback component. However, that feedback needs to be maintained in memory in a context of interference. In sum, the "frontal lobe metaphor" clearly dissociates the General Memory components from those of executive function. However, the line between these types of tasks is not drawn easily in a normal population; the difference between executive functions and nonexecutive processes necessary for them may appear as one of level, rather than quality, of processing. Nonetheless, the fact that our results were obtained despite a rigorous control for these IQ subtests and General Memory supports even more strongly the importance of poor executive functions in a history of physical aggression.

This focus on nonexecutive processes that may affect executive functions and the notion of effortful processing brings this discussion to a second set of factors that needs to be examined as alternatives or complementary hypotheses to the "frontal lobe metaphor". The current assessment did not measure any form of energy expenditure. It is possible that those participants who performed more poorly have done so because they did not feel like putting any effort in achieving success. It is also possible that they tried hard but failed. Current testing procedures are not well designed to partial out those processes. It would be very useful to identify the conditions that will affect performance on executive function tests. For example, Newman and colleagues (1998) have formulated a theory to explain response modulation deficits in psychopaths. These authors have repeatedly shown that, once a dominant response is established, psychopaths have difficulty automatically attending to peripheral cues that would enable nonpsychopaths to alter their response. Since the information is not attended to, it may not be processed at higher levels. This difficulty is a form of perseveration, but in this case, the process at fault would not be due to a lack of effortful processing and may theoretically occur in individuals with otherwise adequate executive functions (Séguin et al., 1999). Newman's position is akin to that of Barkley (1997), who indicates that unless inhibition occurs there will not be adaptive use of executive functions. Finally, another factor at play may be impulsivity. Only carefully crafted automated test batteries designed to measure reaction times with welldefined information processing phases will be of help in examining impulsivity. These batteries could also be designed to put constraints on performance such as forcing a participant to pace her or his responses. Pacing the responses could improve the capacity for reflectivity. Newman and others (Backorowski \& Newman, 1990; Newman, Kosson, \& Patterson, 1992; Patterson \& Newman, 1993) have shown improved performance under certain conditions when delays to responding were imposed and when contingencies were manipulated.

Acknowledgements - The National Science and Engineering Research Council of Canada and the Fonds pour la Formation des Chercheurs et l'Aide à la Recherche (FCAR: Québec) made this collaborative work possible by scholarships to the first author. The Social Sciences and Humanities Research Council of Canada, FCAR and the Conseil Québécois de la Recherche Sociale funded the project and the research centre. Thanks are extended to the boys and their families, to the Commission des Écoles Catholiques de Montréal, to the Research Unit on Children's Psychosocial Maladjustment, to the Research Team on Prevention and treatment of Substance Abuse, to Denis Larocque, to Michael Petrides, and to three anonymous reviewers.

\section{References}

Achenbach, T. M., McConaughy, S. H., \& Howell, C. T. (1987). Child/adolescent behavioral and emotional problems: Implications of cross-informant correlations for situational specificity. Psychological Bulletin, 101, 213-232.

American Psychiatric Association. (1987). Diagnostic and statistical manual of mental disorders (3rd ed.-revised). Washington, DC: Author.

Bachorowski, J.-A., \& Newman, J. P. (1990). Impulsive behavior: Effects of personality and goal salience. Journal of Personality and Social Psychology, 58, 512-518.

Barkley, R. A. (1997). Behavioral inhibition, sustained attention, and executive functions: Constructing a unifying theory of ADHD. Psychological Bulletin, 121, 65-94.

Biederman, J., Faraone, S. V., Milberger, S., Curtis, S., Chen, L., Marrs, A., Ouellette, C., Moore, P., \& Spence, T. (1996). Predictors of persistence and remission of ADHD into adolescence: Results from a four-year prospective follow-up study. Journal of the American Academy of Child and Adolescent Psychiatry, 35, 343-351.

Biederman, J., Faraone, S. V., Taylor, A., Sienna, M., Williamson, S., \& Fine, C. (1998). Diagnostic continuity between child and adolescent ADHD: Findings from a longitudinal clinical sample. Journal of the American Academy of Child and Adolescent Psychiatry, 37, 305-313.

Breton, J.-J., Bergeron, L., Valla, J.-P., Lépine, S., Houde, L., \& Gaudet, N. (1995). Do children aged 9 through 11 years understand the DISC version 2.25 questions? Journal of the American Academy of Child and Adolescent Psychiatry, 34, 946-954.

Costello, E. J., Edelbrock, C. S., \& Costello, A. J. (1985). Validity of the NIMH Diagnostic Interview Schedule for Children: A comparison between psychiatric and pediatric referrals. Journal of Abnormal Child Psychology, 13, 579-595.

Delis, D. C., Squire, L. R., Bihrle, A., \& Massman, P. (1992). Componential analysis of problem-solving ability: Performance of patients with frontal lobe damage and amnesic patients on a new sorting test. Neuropsychologia, 30, 683-697.

Dodge, K. A., \& Coie, J. D. (1987). Social-informationprocessing factors in reactive and proactive aggression in children's peer groups. Journal of Personality and Social Psychology, 53, 1146-1158. 
Dodge, K. A., Lochman, J. E., Harnish, J. D., Bates, J. E., \& Pettit, G. S. (1997). Reactive and proactive aggression in school children and psychiatrically impaired chronically assaultive youth. Journal of Abnormal Psychology, 106, $37-51$.

Edelbrock, C. S., Costello, A. J., Dulcan, M. K., Kalas, R., \& Conover, N. (1985). Age differences in the reliability of the psychiatric interview of the child. Child Development, 56, 265-275.

Fisher, P. W., Shaffer, D., Piacentini, J. C., Lapkin, J., Kafantaris, V., Leonard, H., \& Herzog, D. B. (1993). Sensitivity of the Diagnostic Interview Schedule for Children, 2nd ed. (DISC 2.1) for specific diagnoses of children and adolescents. Journal of the American Academy of Child and Adolescent Psychiatry, 32, 666-673.

Giancola, P. R. (1995). Evidence for dorsolateral and orbital prefrontal cortical involvement in the expression of aggressive behavior. Aggressive Behavior, 21, 431-450.

Giancola, P. R., Mezzich, A. C., \& Tarter, R. E. (1998). Executive cognitive functioning, temperament, and antisocial behavior conduct-disordered adolescent females. Journal of Abnormal Psychology, 107, 629-641.

Giancola, P. R., \& Zeichner, A. (1994). Neuropsychological performance on tests of frontal-lobe functioning and aggressive behavior in men. Journal of Abnormal Psychology, $103,832-835$.

Gray, J. A. (1987). The psychology of fear and stress (2nd ed.). Cambridge: Cambridge University Press.

Hodges, K. (1993). Structured interviews for assessing children. Journal of Child Psychology and Psychiatry, 34, 49-68.

Jensen, P. S., Roper, M., Fisher, P. W., Piacentini, J. C., Canino, G., Richters, J. E., Rubio-Stipec, M., Dulcan, M., Goodman, S., Davies, M., Rae, D., Schaffer, D., Bird, H., Lahey, B. B., \& Schwab-Stone, M. (1995). Test-retest reliability of the Diagnostic Interview Schedule for Children (DISC 2.1): Parent, child, and combined algorithms. Archives of General Psychiatry, 52, 61-71.

Kandel, E., Mednick, S. A., Kirkegaard-Sorensen, L., Hutchings, B., Knop, J., Rosenberg, R., \& Schulsinger, F. (1988). IQ as a protective factor for subjects at high risk for antisocial behavior. Journal of Consulting and Clinical Psychology, 56, 224-226.

Lau, M. A., Pihl, R. O., \& Peterson, J. B. (1995). Provocation, acute alcohol intoxication, cognitive performance, and aggression. Journal of Abnormal Psychology, 104, 150-155.

Lezak, M. D. (1985). Neuropsychological assessment. In J. A. M. Frederiks (Ed.), Handbook of clinical neurology, Vol. 1 (45): Clinical neuropsychology (pp. 515-530). New York: Elsevier.

Luria, A. R., \& Homskaya, E. D. (1964). Disturbance in the regulative role of speech with frontal lobe lesions. In J. M. Warren \& K. Akert (Eds.), The frontal granular cortex and behavior (pp. 353-371). New York: McGraw-Hill.

Lynam, D. R., Moffitt, T. E., \& Stouthamer-Loeber, M. (1993). Explaining the relation between IQ and delinquency: Class, race, test motivation, school failure, or self-control? Journal of Abnormal Psychology, 102, 187-196.

McGee, R., Williams, S., Moffitt, T. E., \& Anderson, J. (1989). A comparison of 13-year-old boys with attention deficit and/or reading disorder on neuropsychological measures. Journal of Abnormal Child Psychology, 17, 37-53.

Milner, B., \& Petrides, M. (1984). Behavioural effects of frontallobe lesion in man. Trends in Neuroscience, 7, 403-407.

Milner, B., Petrides, M., \& Smith, M. L. (1985). Frontal lobes and the temporal organization of memory. Human Neurobiology, 4, 137-142.

Newman, J. P. (1998). Psychopathic behavior: An information processing perspective. In D. J. Cooke, A. E. Forth, \& R. D.
Hare (Eds.), Psychopathy: Theory, research, and implications for society (pp. 81-104). Dordrecht, The Netherlands: Kluwer.

Newman, J. P., Kosson, D. S., \& Patterson, C. M. (1992). Delay of gratification in psychopathic and nonpsychopathic offenders. Journal of Abnormal Psychology, 101, 630-636.

Offord, D. R., Boyle, M. H., \& Racine, Y. (1989). Ontario Child Health study: Correlates of disorder. Journal of the American Academy of Child and Adolescent Psychiatry, 28, 856-860.

Patterson, C. M., \& Newman, J. P. (1993). Reflectivity and learning from aversive events: Toward a psychological mechanism for the syndromes of disinhibition. Psychological Review, 100, 716-736.

Pennington, B. F., \& Ozonoff, S. (1996). Executive functions and developmental psychopathology. Journal of Child Psychology and Psychiatry, 37, 51-87.

Petrides, M. (1985). Deficits on confidential associative-learning tasks after frontal- and temporal-lobe lesions in man. Neuropsychologia, 23, 601-614.

Petrides, M. (1990). Nonspatial conditional learning impaired in patients with unilateral frontal but not unilateral temporal lobe excisions. Neuropsychologia, 28, 137-149.

Petrides, M. (1995). Functional organization of the human frontal cortex for mnemonic processing. Evidence from neuroimaging studies. Annals of the New York Academy of Sciences, 769, 85-96.

Petrides, M., Alivisatos, B., \& Evans, A. C. (1995). Functional activation of the human ventrolateral frontal cortex during mnemonic retrieval of verbal information. Proceedings of the National Academy of Sciences of the United States of America, 92, 5803-5807.

Petrides, M., Alivisatos, B., Evans, A. C., \& Meyer, E. (1993a). Dissociation of human mid-dorsolateral from posterior dorsolateral frontal cortex in memory processing. Proceedings of the National Academy of Sciences of the United States of America, 90, 873-877.

Petrides, M., Alivisatos, B., Meyer, E., \& Evans, A. C. (1993b). Functional activation of the human frontal cortex during the performance of verbal working memory tasks. Proceedings of the National Academy of Sciences of the United States of America, 90, 878-882.

Petrides, M., \& Milner, B. (1982). Deficits on subject-ordered tasks after frontal- and temporal-lobe lesions in man. Neuropsychologia, 20, 249-262.

Pihl, R. O., \& Peterson, J. B. (1991). Attention-deficit hyperactivity disorder, childhood conduct disorder, and alcoholism: Is there an association? Alcohol Health and Research World, 15, 25-31.

Roberts, R. E., Solovitz, B. L., Chen, Y.-W., \& Casat, C. (1996). Retest stability of DSM-III-R diagnoses among adolescents using the Diagnostic Interview for Children (DISC-2.1C). Journal of Abnormal Child Psychology, 24, 349-362.

Sattler, J. M. (1988). Assessment of children (3rd ed.). San Diego, CA: Sattler.

Schwab-Stone, M. E. (1995). Discussion of: "Do children aged 9 through 11 years understand the DISC version 2.25 questions?". Journal of the American Academy of Child and Adolescent Psychiatry, 34, 954-956.

Schwab-Stone, M. E., Fallon, T., Briggs, M., \& Crowther, B. (1994). Reliability of diagnostic reporting for children aged 6-11 years: A test-retest study of the Diagnostic Interview Schedule for Children-Revised. American Journal of Psychiatry, 151, 1048-1054.

Schwab-Stone, M. E., Fisher, P. W., Piacentini, J. C., Shaffer, D., Davies, M., \& Briggs, M. (1993). The Diagnostic Interview Schedule for Children-Revised version (DISC-R): 
II. Test-retest reliability. Journal of the American Academy of Child and Adolescent Psychiatry, 32, 651-657.

Séguin, J. R., Arseneault, L., Boulerice, B., \& Tremblay, R. E. (1999). Response perseveration in adolescent boys with a history of physical aggression: A test of the response modulation hypothesis. Manuscript submitted for publication.

Séguin, J. R., Pihl, R. O., Boulerice, B., Tremblay, R. E., \& Harden, P. W. (1996). Pain sensitivity and stability of physical aggression in boys. Journal of Child Psychology and Psychiatry, 37, 823-834.

Séguin, J. R., Pihl, R. O., Harden, P. W., Tremblay, R. E., \& Boulerice, B. (1995). Cognitive and neuropsychological characteristics of physically aggressive boys. Journal of Abnormal Psychology, 104, 614-624.

Shaffer, D. (1994). Debate and argument: Structured interviews for assessing children. Journal of Child Psychology and Psychiatry, 35, 783-784.

Spreen, O., Risser, A. H., \& Edgell, D. (1995). Developmental neuropsychology. New York: Oxford.

Squire, L. R., \& Zola-Morgan, S. M. (1991). The medial temporal lobe memory system. Science, 253, 1380-1386.

Stuss, D. T. (1992). Biological and psychological development of executive functions. Brain and Cognition, 20, 8-23.

Stuss, D. T., \& Benson, D. F. (1986). The frontal lobes. New York: Raven.

Tabachnick, B. G, \& Fidell, L. S. (1989). Using multivariate statistics (2nd ed.). New York: Harper Collins.

Tremblay, R. E., Loeber, R., Gagnon, C., Charlebois, P., Larivée, S., \& LeBlanc, M. (1991). Disruptive boys with stable and unstable high fighting behavior patterns during junior elementary school. Journal of Abnormal Child Psychology, 19, 285-300.

Valla, J.-P., Breton, J.-J., Bergeron, L., Berthiaume, C., SaintGeorges, M., Daveluy, C., Tremblay, V., Lambert, J., Houde, L., \& Lépine, S. (1994). Enquête québécoise sur la santé mentale des jeunes de 6 à 14 ans 1992: Rapport de synthèse [Quebec mental health survey of youth aged 6 to 14 years old 1992: Synthesis report]. Quebec: Hôpital Rivière-desPrairies et Santé Québec, en collaboration avec le Ministère de la Santé et des Services sociaux, Gouvernement du Québec.

Wechsler, D. (1974). Manual for the Wechsler Intelligence Scale for Children-Revised. San Antonio, TX: The Psychological Corporation.

Wechsler, D. (1987). Wechsler Memory Scale-Revised. New York: Psychological Corporation.

Welsh, M. C., \& Pennington, B. F. (1988). Assessing frontal lobe functioning in children: Views from developmental psychology. Developmental Neuropsychology, 4, 199-230.

White, J. L., Moffitt, T. E., \& Silva, P. A. (1989). A prospective replication of the protective effects of IQ in subjects at high risk for juvenile delinquency. Journal of Consulting and Clinical Psychology, 57, 719-724.

Wiegersma, S., van der Scheer, E., \& Human, R. (1990). Subjective ordering, short-term memory, and the frontal lobes. Neuropsychologia, 28, 95-98.

Zelazo, P. D., Carter, A., Reznick, J. S., \& Frye, D. (1997). Early development of executive function: A problem-solving framework. Review of General Psychology, 1, 198-226.

Manuscript accepted 1 June 1999 